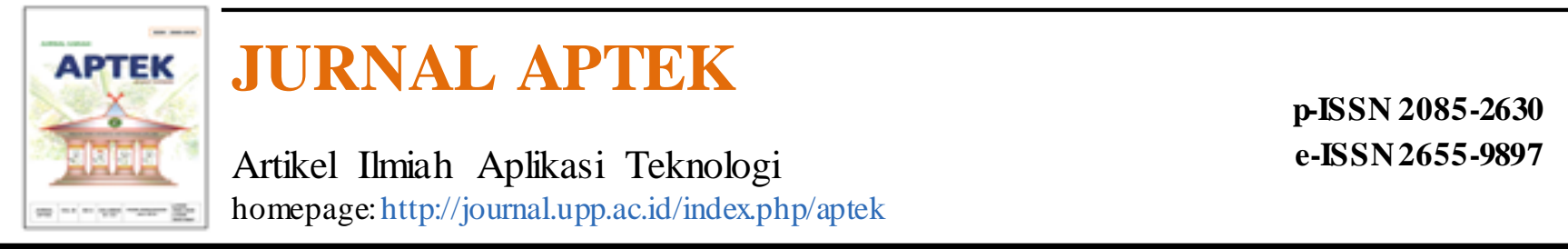

\title{
Penentuan Nilai Hierarki Rancang Bangun Reaktor Pembuat Foaming Agent Pemadam Kebakaran Lahan Gambut Menggunakan AHP dengan Aplikasi Expert Choice
}

\author{
Purwo Subekti
}

Program Studi Teknik Mesin, Universitas Pasir Pengaraian, Kab. Rokan Hulu, Riau

\section{INFO ARTIKEL}

Histori artikel:

Diajukan 23 November 2020

Diterima dalam bentuk revisi 13

Desember 2020

\begin{abstract}
A B S T R A K
Usaha untuk memudahkan proses pengambilan keputusan dalam rancang bangun pembuatan reaktor pembuat foaming agent pemadam kebakaran lahan gambut, perlu ditentukan bobot struktur setiap tahapan kegiatan yang dilakukan. Tujuan dari penelitian ini adalah untuk mendapatkan nilai masing-masing kriteria dan altematif untuk mempercepat proses pengambilan keputusan setiap aktivitas kegiatan rancang bangun. Hierarki kriteria tersebut adalah studi referensi, pengembangan data perancangan, gambar dan simulasi, manufaktur, commissioning dan validasi. Sedangkan untuk hierarki altematif adalah andal, safety dan operasional mudah. Metode yang digunakan untuk menentukan nilai bobot tersebut adalah menggunakan AHP (Analytic Hierarchy Process), dengan aplikasi Expert Choice. Hasil pengolahan data penilaian bobot prioritas tertinggi adalah kriteria manufaktur nilainya 0.313 , kemudian hasil bobot altematif tertinggi adalah andal nilainya 0.417 . Hasil analis is konsistensi tingkat kriteria adalah 4\%, karena nilai konsistensi di bawah $10 \%$ maka penilaian prioritas kriteria dapat diterima. Dari hasil tersebut terlihat bahwa kriteria manufaktur merupakan prioritas yang perlu mendapat perhatian dalam proses rancang bangun pembuatan reaktor pembuat foaming agent, dengan hasil produk yang dihasilkan dituntut memiliki tingkat keandalan yang perlu diperhatikan.
\end{abstract}

Kata kunci: AHP, foaming agent, pemadamkebakaran, rancang bangun, reaktor

\section{E- M A I L}

purwos73@gmail.com

\section{$A B S T R A C T$}

For efforts to facilitate the decision-making process in the design and construction of a peatland fire suppression agent foam reactor, it is necessary to determine the weight of the structure for each stage of the activity carried out. This study aims to obtain the value of each criterion and alternative to accelerate the decision-making process of each design activity. These criteria are study criteria, design data development, drawings and simulations, manufacturing, commissioning, and validation. Whereas the alternative hierarchy is a reliable, safe, and easy operation. The method used to determine the weight value is to use AHP (Analytical Hierarchy Process), with the Expert Choice application. The result of data processing of the highest priority weight assessment is the manufacturing criteria with a value of 0.313 , then the result of the highest alternative weighting is reliable with a value is 0.417. The consistency analysis of the criteria level is 4\%. Because the consistency value is below 10\%, the weighting criteria priority assessment can be accepted. From these results, it can be seen that manufacturing is a priority that needs attention in the process of designing a reactor for making foaming agent, with the resulting product is required to have a level of reliability that needs attention.

Keywords: AHP, fire suppression, foaming agent, design, reactor 


\section{PENDAHULUAN}

Pengukuran nilai proses rancang bangun pembuatan produk perlu dilakukan dalam rangka untuk mengetahui bobot setiap tahapan yang dilakukan. Mengetahui nilai masing-masing tahapan yang dilakukan akan mempercepat dalam pengambilan keputusan setiap proses kerja, sehingga target atau sasaran yang diharapkan lebih cepat tercapai. Pengambilan keputusan untuk eksekusi setiap kriteria langkah kerja dalam tahapan pembuatan produk baru perlu mempertimbangkan kajian secara sistematis, hal tersebut dilakukan sebagai upaya mengurangi kesalahan dan kerugian dalam setiap tahapan proses kerja [1].

Diantara pengukuran bobot tahapan proses pembuatan produk adalah penentuan nilai hierarki rancang bangun reaktor pembuat foaming agent pemadam kebakaran lahan gambut. Perancangan reaktor untuk penggunaan tersebut, perlu dilakukan dalam rangka untuk memudahkan proses manufaktur dan commisioning serta evaluasi. Tahapan rencana kegiatan rancang bangun disusun dan dilaksanakan dengan benar berdasarkan prosedur baku yang dibuat, sehingga produk yang akan dihasilkan sesuai dengan yang diharapkan. Untuk itu perlu penetapan hierarki prosedur dalam pelaksanaan tahapan rancang bangun, penentuan hierarki rancang bangun reaktor tersebut merupakan implementasi dari kajian-kajian yang telah dilakukan oleh peneliti pendahulu [2], [3], [4] dan [5] terkait foaming agent untuk aplikasi pemadam kebakaran lahan gambut. Penentuan hierarki bertujuan untuk mengurai elemen-elemen yang dianggap sebagai masalah dalam pengambilan keputusan untuk merancang dan membuat reaktor, dengan menentukan nilai dari elemen-elemen tersebut akan dihasilkan pilihan bobot keputusan dalam setiap tahapan proses [6].

Tujuan dari penelitian ini adalah untuk mengukur nilai struktur tahapan proses rancang bangun reaktor pembuat foaming agent, dengan diketahui bobot setiap tahapan yang dilakukan diharapkan dapat mempercepat proses pengambilan keputusan dalam melaksanakan kegiatan rancang bangun. Metode yang digunakan untuk menentukan nilai bobot struktur tersebut adalah menggunakan Analytical Hierarchy Process (AHP), dengan aplikasi Expert Choice 2011.

\section{MATERIAL DAN METODE}

Untuk mengukur nilai bobot struktur tahapan proses rancang bangun reaktor pembuat foaming agent menggunakan AHP, perlu penetapan hierarki prosedur dalam pelaksanaan tahapan rancang bangun, struktur hierarki tersebut adalah penentuan sasaran, kriteria, tujuan dan alternatif. Rincian struktur hierarki tersebut disajikan pada Gambar 1. Penentuan nilai hierarki rancang bangun reaktor pembuat foaming agent pemadam kebakaran lahan gambut, merupakan pengembangan dari hasil kajian yang dilakukan oleh peneliti sebelumnya [1] dan [7]. Pengembangan dilakukan untuk menyesuaikan dengan kondisi rencana kegiatan rancang bangun yang akan dilakukan.

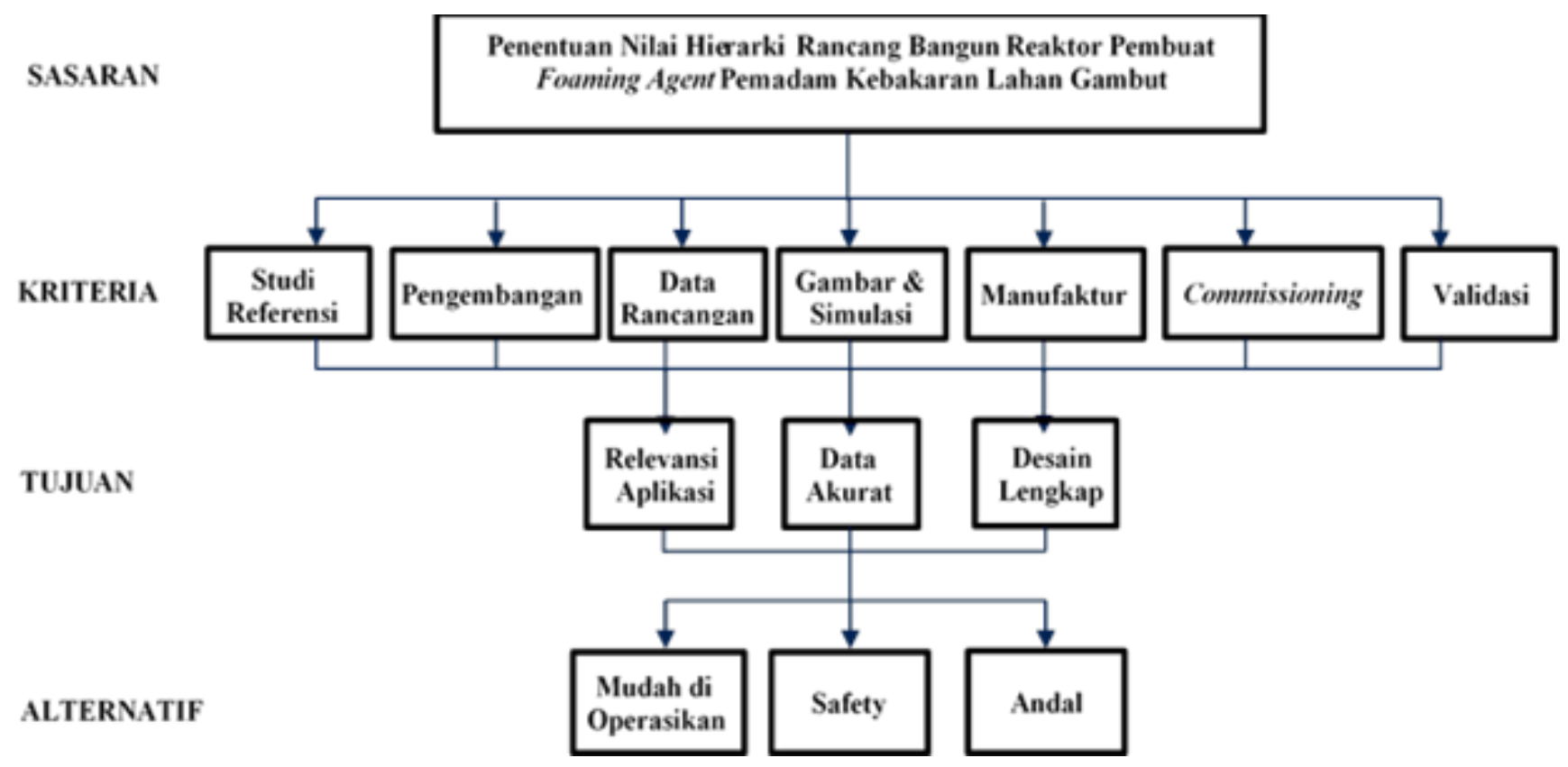

Gambar 1. Penentuan nilai hierarki rancang bangun reaktor pembuat foaming agent pemadam kebakaran lahan gambut 
Dalam mendapatkan data untuk di olah maka perlu adanya responden yang melakukan penilaian terhadap kriteria dan alternatif menguasai permasalahan pada latar belakang tentang Penentuan Prioritas rancang bangun reaktor pembuat foaming agent. Data dari responden didapat dengan cara melakukan wawancara kepada para pihak yang berkompeten dalam bidang sintesis, formulasi dan rancang bangun tentang rekayasa teknik. Pertanyaan dalam wawancara di sesuaikan dengan isi dari kuesioner dan disampaikan dengan jelas kriteria penilaian dari setiap pertanyaan, jumlah responden dalam hal ini sebanyak dua orang. Pengisian kuesioner ini bertujuan untuk menentukan alternatif prioritas tahapan rancang bangun, landasan utama pengisian ini adalah hierarki (struktur AHP) dengan komponen-komponen yang telah disusun sebagaimana disajikan pada Tabel 1. Keluaran dari kuesioner ini adalah memprioritaskan salah satu elemen berdasarkan pendapat responden [8].

Tabel 1. Penilaian kuesioner yang telah di isi oleh responden [7] dan [8]

\begin{tabular}{|c|c|l|c|c|c|c|c|}
\hline Kriteria & $\begin{array}{c}\text { Studi } \\
\text { Referensi }\end{array}$ & Pengembangan & $\begin{array}{c}\text { Data } \\
\text { Perancangan }\end{array}$ & $\begin{array}{c}\text { Gambar dan } \\
\text { Simulasi }\end{array}$ & Manufaktur & Commissioning & Validasi \\
\hline Studi Referensi & & & & & & & \\
\hline Pengembangan & & & & & & & \\
\hline $\begin{array}{c}\text { Data } \\
\text { Perancangan }\end{array}$ & & & & & & \\
\hline $\begin{array}{c}\text { Gambar dan } \\
\text { Simulasi }\end{array}$ & & & & & & & \\
\hline Manufaktur & & & & & & & \\
\hline Commissioning & & & & & & & \\
\hline Validasi & & & & & & \\
\hline
\end{tabular}

Dalam pengisian kuesioner penilaian dalam tabel di atas, responden diminta untuk membandingkan mana yang lebih penting dari elemen faktor A (vertikal) dengan elemen faktor B (horizontal), lalu memberikan bobot berdasarkan skala penilaian [7]. Skala penilaian dalam penelitian ini disajikan pada Tabel 2. Tabel tersebut menyajikan nilai perbandingan dan penjabaran dari nilai tersebut, nilai dan definisi yang disajikan merupakan modifikasi dari peneliti sebelumnya [7].

Tabel 2. Definisi dari skala nilai perbandingan masing-masing kriteria*

\begin{tabular}{|l|l|}
\hline $\begin{array}{c}\text { Nilai } \\
\text { Perbandingan }\end{array}$ & \multicolumn{1}{c|}{ Definisi } \\
\hline 1 & A sama penting dengan B \\
\hline 3 & A sedikit lebih penting dari B \\
\hline $1 / 3$ & B sedikit lebih penting dari A \\
\hline 5 & A jelas lebih penting dari B \\
\hline $1 / 5$ & B jelas lebih penting dari A \\
\hline 7 & A sangatjelas lebih penting daripada B \\
\hline $1 / 7$ & B sangat jelas lebih penting daripada \\
\hline 9 & A mutlak lebih penting daripada B \\
\hline $1 / 9$ & B mutlak lebih penting daripada A \\
\hline $\begin{array}{l}2,4,6,8 \text { atau } \\
1 / 2,1 / 4,1 / 6\end{array}$ & $\begin{array}{l}\text { Diberikan apabila terdapat sedikit } \\
\text { perbedaan dengan patokan diatas }\end{array}$ \\
\hline
\end{tabular}

*Modifikasidari [7]

Setelah responden melakukan pengisian, kemudian di input kedalam aplikasi Expert Choice untuk mengukur nilai struktur setiap tahapan proses yang akan dilakukan dalam rancang bangun reaktor pembuat foaming agent. Dengan diketahuinya bobot setiap tahapan yang dilakukan akan dihasilkan nilai prioritas setiap kriteria untuk menentukan tingkat kepentingan dalam pengambilan keputusan dalam melaksanakan tahapan kegiatan [9] dan [10].

\section{HASIL DAN PEMBAHASAN}

Hasil olah data dengan menggunakan AHP yang di bantu dengan perangkat lunak Expert Choice 2011, di dapatkan penilaian perbandingan kriteria kombinasi responden dengan bobot prioritas tertinggi adalah kriteria manufaktur dengan nilai $31.3 \%$. Untuk urutan kedua sampai ketujuh masing-masing adalah data perencanaan, pengembangan, gambar dan simulasi, commissioning, validasi dan studi referensi dengan nilai masing-masing adalah $15.9 \%, 15.1 \%, 11.4 \%$, $11.3 \%, 8.8 \%$ dan $6.1 \%$, seperti disajikan pada Gambar 2. Selain nilai bobot kriteria, gambar tersebut juga menyajikan hasil analisis konsistensi nilai tingkat kriteria. Hasil analisis konsistensi adalah 4\%, nilai konsistensi perlu dilihat apakah nilainya lebih besar atau kurang dari $10 \%$. Jika nilai konsistensi yang dihasilkan di bawah 10\% maka matrik penilaian prioritas kriteria dapat diterima dan jika tingkat kriteria lebih besar dari $10 \%$ perhitungan tidak diterima, hal ini diindikasikan penilaian kuesioner diisi secara random [6].

Nilai bobot yang di hasilkan memperlihatkan bahwa kriteria manufaktur merupakan prioritas dalam perhatian dalam tahapan rancang bangun reaktor 
pembuat foaming agent pemadam kebakaran lahan gambut. Meskipun kriteria lain nilai bobotnya di baw ah nilai bobot kriteria manufaktur, dalam kegiatan tahapan rancano hanoun cama_cama memiliki tinckat setiap tahapan proses kegiatan diperlukan perlakuan sesuai prosedur yang benar dalam rangka untuk mendapatkan hasil rancang bangun yang diharapkan [111

kepenting

Priorities with respect to

Combined

Nila

i bobot

priorita

s dari

kriteria

sudah

diketah

ui,

\section{PENENTUAN NIIAI HIERARKI RANCANG BANGUN REAKTOR PEMBUAT FOAMING AGE.}

\section{Combined}

PENEN TUAN NIIAI HII RARKI RAICNIG BANGUN REAKTOR PEMBUAT FOAMING AGE.

untuk

selanjut

nya

adalah

\begin{tabular}{l} 
Studi Referensi \\
Penqembanqan \\
Data Perancancan \\
Ganbar dan Simulasi \\
\hline Manuf aktur \\
Komisioning \\
Validasi \\
Inconsistency $=\mathbf{0 , 0 4}$ \\
\hline with 0 missina iudaments. \\
\hline
\end{tabular}

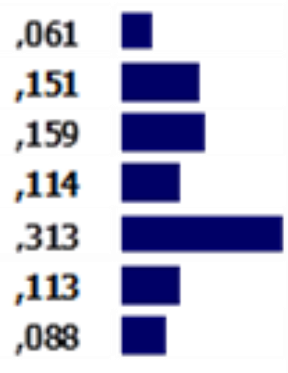

menghi

tung

Gambar 2. Hasil pengolah data untuk penilaian kuesioner perbandingan kriteria

bobot

prioritas alternatif. Alternatif untuk menentukan prioritas rancang bangun ada tiga yaitu operasional mudah, safety dan andal. Ketiga alternatif tersebut merupakan pilihan untuk menentukan mana yang memiliki potensi dalam penentuan prioritas tahapan rancang bangun yang akan dilakukan, penentuan nilai bobot alternatif berdasarkan sub-kriteria [12].

Penentuan bobot prioritas alternatif di hitung berdasarkan hasil data olah dari penilaian kuesioner yang telah dilakukan oleh para responden, dari Gambar 3 terlihat bahwa data olah penilaian bobot alternatif andal dengan nilai sebesar $40.7 \%$ kemudian alternatif pilihan kedua safety dengan nila bobot $30.2 \%$ dan ketiga adalah operasional mudah dengan nilai sebesar 29.1\%. Hasil pembobotan tersebut memperlihatkan bahwa produk reaktor yang akan dibuat memprioritaskan keandalan dalam operasional pembuatan foaming agent untuk aplikasi pada pemadam kebakaran lahan gambut. Namun demikian alternatif lain juga menjadi perhatian dalam proses tahapan rancang bangun, sehingga ketiga alternatif saling terkait dalam menghasilkan produk [13].

\section{Combined irstanos *- Synthes is st thesped to: PENEITUAN NILAI HIERARKI RANCANG BANGUN REAKTOR PEMEUAT FOAMNG AGEIT PEMAD AMKEEAKARAN LAHAN GAMBUT}

\section{Overall hoons stenoy $=, 04$}

\begin{tabular}{|l|r|}
\hline OperasionalMudah & 291 \\
\hline Safety & 302 \\
\hline Andal & 407 \\
\hline
\end{tabular}

Gambar 3. Hasil pengolah data untuk penilaian bobot prioritas alternatif

Keandalan reaktor dalam operasinya menjadi nilai prioritas tertinggi dalam proses kegiatan tahapan rancang bangun, hal tersebut didasarkan selain hasil analisis sensitivitas yang disajikan Gambar 4 juga berdasarkan prinsip bahwa produk yang dihasilkan mampu memenuhi kebutuhan dan keinginan konsumen
[14]. Analisis sensitivitas dilakukan untuk mengetahui konsistensi dan ketahanan kriteria yang dipilih dari parameter-parameter kriteria yang ada. Selain itu, dari analisis tersebut dapat diketahui nilai perubahan terkecil jika ada informasi terbaru dari nilai setiap kriteria [15]. 


\section{Performance Sensitivity for nodes below: PENENTUAN NILAI HIERARKI RANCANG BANGUN REAKTOR PEMBUAT FOAMING AGENT PEMADAM KEBAKARAN LAHAN GAMBUT}

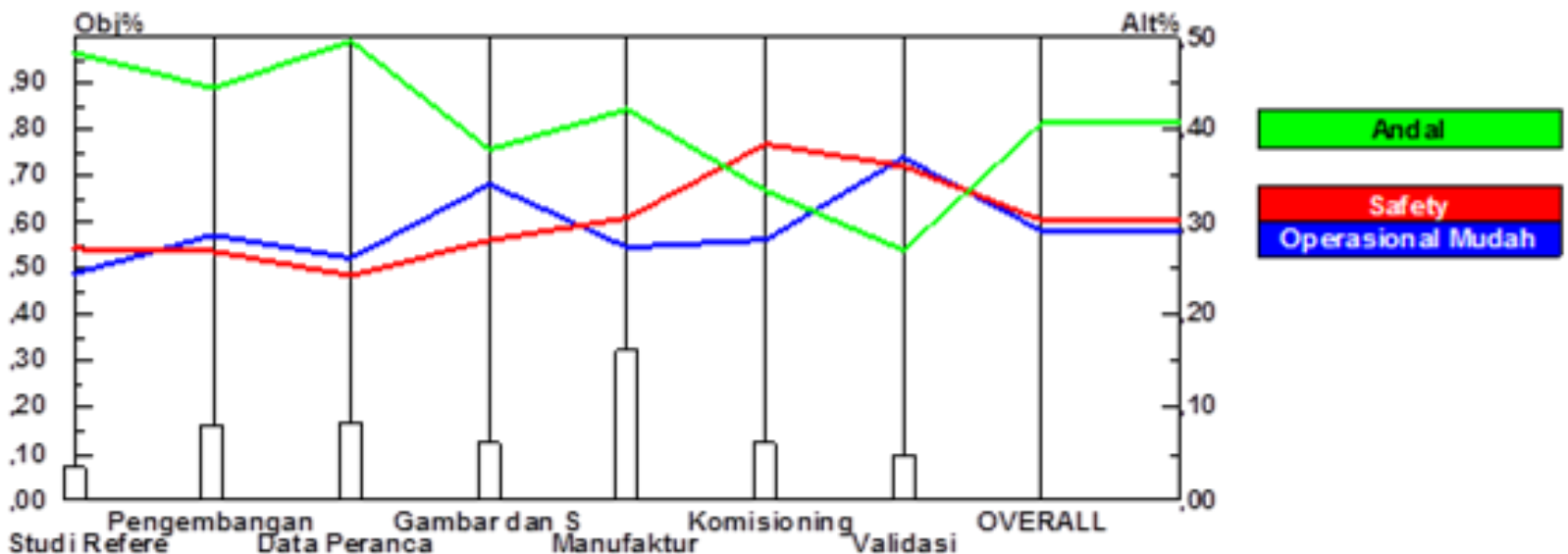

Gambar 4. Hasil analisis sensitivitas

\section{KESIMPULAN}

Hasil pengolahan data penilaian perbandingan kriteria kombinasi responden dengan bobot prioritas kriteria tertinggi adalah kriteria manufaktur nilainya $31.3 \%$, kemudian nilai konsistensi tingkat kriteria adalah $4 \%$, karena nilai konsistensi di bawah $10 \%$ maka matrik penilaian prioritas kriteria dapat diterima. Sedangkan hasil bobot alternatif tertinggi adalah andal dengan nilai $40.7 \%$. Dari hasil tersebut terlihat bahwa kriteria manufaktur merupakan prioritas yang perlu mendapat perhatian dalam proses rancang bangun pembuatan reaktor pembuat foaming agent, dengan produk yang dihasilkan dituntut memiliki tingkat keandalan yang perlu diperhatikan. Pemeringkatan nilai kriteria dilakukan untuk memudahkan dalam penentuan keputusan prioritas dalam proses rancang bangun.

\section{UCAPAN TERIMAKASIH}

Ucapan terimakasih saya sampaikan kepada Prof. Erliza Hambali, Prof. Ani Suryani, Dr. Prayoga Suryadarma, Prof. Bambang Hero Saharjo dan Dr. Mira Rivai atas bantuan dan sarana selama ini.

\section{DAFTAR PUSTAKA}

[1] Marimin, Analisa Sistem dan Pengambilan Keputusan, Modul I: Konsep Sistem dan Teori Pengambilan Keputusan. Bogor: Departemen Teknologi Industri Pertanian, Fakultas Teknik Institut Pertanian Bogor, 2012. 33299871Modul-1-sistem-keputusan-modul-oleh.html.

[2] Japan International Cooperation Agency, Standar Prosedur Operasional terkait Teknik
Pemadaman Api Lahan Gambut dan Kebakaran Hutan. 2016.

http://www.env.kitakyuu.ac.jp/ja/shoubou/img/JICA PJ_SOP_Indonesian.pdf.

[3] P. Subekti, E Hambali, A. Suryani dan P. Suryadarma, "Potential production of palm oilbased foaming agent as fire extinguisher of peatlands in Indonesia: Literature review," 2017. doi :10.1088/1755-1315/65/1/012038.

[4] P. Subekti, E. Hambali, A. Suryani, P. Suryadarma, B. H. Saharjo dan M. Rivai, "The Formulation of Foaming Agents from Palm Oil Fatty Acid and Performance Test on Peat Fires," pp. 95-100, 2019. doi:10.3775/jie.98.95.

[5] P. Subekti, E. Hambali, A. Suryani, P. Suryadarma, B. H. Saharjo dan M. Rivai, "The effects of magnesium sulphate addition into foaming agents resulted from palm oil fatty acid saponification in the performance of peat fire suppression," 2020. doi:10.1088/17551315/460/1/012028.

[6] A. Ishizaka dan A. Labib, "Analytic Hierarchy Process and Expert Choice: Benefits and Limitations," ORInsight, no. December, 2009. doi: 10.1057/ori.2009.10.

[7] H. Taherdoost, "Decision Making Using the Analytic Hierarchy Process ( AHP ); A Step by Step," no. January 2017, 2018. https://www.iaras.org/iaras/filedow nloads/ijems 12017/007-0034(2017).pdf.

[8] T. L. Saaty, "Decision making with the analytic hierarchy process," vol. 1, no. 1, 2008. doi: 10.1504/IJSSCI.2008.017590.

[9] Y. A. Pranoto, M. A. Muslim dan N. Hasanah, "Rancang Bangun dan Analisis Decision 
Support System Menggunakan Metode Analytical Hierarchy Process untuk Penilaian Kinerja Karyawan," vol. 7, no. 1, pp. 91-96, 2013.

https://jurnaleeccis.ub.ac.id/index.php/eeccis/art icle/view/209/181.

[10] E. Choic e $\mathcal{C}$, "Expert Choice Quict Start Guide," Arlington,VA, USA: Expert Choice $\odot$, Inc, 2004.

[11] E. Harjanto, Manajemen Produksi dan Operasi, 2nd ed. Jakarta: Grasindo, 1999.

12] P. Subekti, E. Hambali, A. Suryani, P. Suryadarma, B. Hero dan M. Rivai, "Selection of Peat Firefighting Foam from Palm Oil Fatty Acid Saponification with Simple Additive Weighting ( SAW ) Method," 2018, pp. 171174.

http://prosiding.bkstm.org/prosiding/2018/RM13.pdf.
[13] A. P. Iraw an, "Perancangan dan Pengembangan Produk Manufaktur," no. November 2017, 2018. https://www.researchgate.net/publication/32804 0816_Perancangan_dan_Pengembangan_Produ k_Manufaktur.

[14] J. A.Schey, Penerjemah: Rines, D. Asih, I. S. Utami dan B. H. Winarno, Proses Manufaktur: Introduction to Manufacturing Processes. Yogyakarta: ANDI, 2009.

[15] M. Yazdani, E. K. Zavadskas, J. Ignatius dan M. D. Abad, "Sensitivity Analysis in MADM Methods : Application of Material Selection," vol. 27, no. 4, pp. 382-391, 2016. doi: 10.5755/j01.ee.27.4.14005. 